\title{
Gratitude, self-monitoring and social intelligence: A prosocial relationship?
}

\author{
Liz Gulliford $^{1}$ • Blaire Morgan ${ }^{2}$ (D) Emily Hemming ${ }^{2}$. Jenny Abbott ${ }^{2}$
}

Published online: 19 July 2019

(C) The Author(s) 2019

\begin{abstract}
To date, gratitude has been discussed as a positive construct that is linked to various prosocial outcomes, including helping behaviours and altruism, as well as intrapersonal and interpersonal gains such as life satisfaction and social bonds. The emphasis on gratitude as positive has created a dearth of research examining its potential shadow side. This current paper attempts to explore gratitude in a more critical light in order to question whether gratitude always functions in a prosocial manner. First, the theoretical relationship between gratitude, ingratiation and impression management behaviours are explored with reference to social intelligence (SI) and self-monitoring as key constructs that might underlie gratitude's shadow side. This argument outlines that the apparent prosocial nature of gratitude might, sometimes, mask manipulative and self-serving goals. Preliminary empirical evidence of the relationship between gratitude, SI and self-monitoring is then provided. In Study 1, three-hundred-and-eleven participants completed self-report measures on gratitude, self-monitoring and social intelligence. The results demonstrate smallto-medium and significant correlational links between these constructs. Study 2 explored whether practicing gratitude can lead to changes in impression management skills, specifically social intelligence, through the design and delivery of a gratitude versus pride intervention. This small scale intervention $(N=36)$ provides the first preliminary evidence that practicing gratitude can function to increase participants' levels of social intelligence. The possible prosocial and manipulative functions of this relationship are discussed alongside suggestions for future research avenues.
\end{abstract}

Keywords Gratitude $\cdot$ Ingratiation $\cdot$ Social intelligence $\cdot$ Emotional intelligence $\cdot$ Positive psychology

\section{Introduction}

Since the turn of the millennium there has been a burgeoning interest in the topic of gratitude. Gratitude has widely been credited to be one of the 'success stories' of positive psychology and 'the quintessential positive psychology trait' (Wood et al.

Electronic supplementary material The online version of this article (https://doi.org/10.1007/s12144-019-00330-w) contains supplementary material, which is available to authorized users.

Blaire Morgan

b.morgan@worc.ac.uk

Liz Gulliford

liz.gulliford@northampton.ac.uk

1 Faculty of Health and Society, University of Northampton, University Drive, Northampton NN1 5PH, UK

2 School of Psychology, University of Worcester, Henwick Grove, Worcester WR2 6AJ, UK
2009, p. 43). Cultivating gratitude is associated with intrapersonal and interpersonal wellbeing. For instance, keeping a gratitude journal has been shown to improve mood in people with a diagnosis of mild to moderate depression (Emmons and McCullough 2003), improve subjective wellbeing in individuals with an eating disorder (Geraghty et al. 2010a), and even help people sleep (Geraghty et al. 2010b). Moreover, gratitude has been shown to build stronger interpersonal relationships at home (Barton et al. 2015) and in the workplace (Waters 2012).

By this point, the prosocial nature of gratitude has been explored within a large number of theoretical and empirical papers and across multiple disciplines including psychology, philosophy, theology and education. Having a grateful disposition has been linked to giving and helping behaviors as well as other prosocial constructs such as empathy, humility and altruism (Algoe et al. 2008; Bartlett and DeSteno 2006; Grant and Gino 2010; Kruse et al. 2014; Naito et al. 2005; McCullough et al. 2008; Tsang 2006). As an explanation for these prosocial links, researchers have described gratitude as entailing moral motivations and reinforcement; receiving benefits from others spurs us on to give to others and receiving messages of gratitude for our 
kind gestures reinforces benevolent acts, thereby increasing the likelihood of these being repeated again in the future (see McCullough et al. 2001). The link between experiencing feelings of gratitude and engaging in prosocial acts like giving and helping is not limited to giving or helping the original benefactor, rather, gratitude is associated with a phenomenon named 'upstream reciprocity' where the prosocial benefits of gratitude ripple out to others (Nowak and Roch 2007).

The purpose of this paper, however, is to critically explore the 'prosocial' nature of gratitude and to outline how some of the functions of this construct might masquerade as prosocial, but could be beneficial to the self as opposed to others. As part of this endeavor, this paper examines the ways in which gratitude might be used for manipulative means and for impression management goals; by doing so this paper also reviews the characterization of gratitude as positive.

While it may be true that many of our experiences of gratitude are positive, there are occasions when our experience of gratitude may have a different affective tone. Although we could feel grateful for a gift, we might suspect the motives of the benefactor. This would give rise to mixed feelings and an ambivalently-valenced experience of gratitude, based on cognitive appraisals of the benefactor's intent. The importance of benefactor intention in providing a benefit was first articulated by Tesser et al. (1968), and was subsequently examined by Wood et al. (2008b)) who identified benefactor intention (alongside the cost to the benefactor and value of the benefit) as socio-cognitive factors involved in appraisals of gratitude.

Beyond the three moderators of intention, cost and value, a number of studies have shown that conceptual differences in understanding gratitude modify the valence ascribed to gratitude (Gulliford and Morgan 2016; Morgan et al. 2017). For instance, on average people report that they would be less grateful for a benefit that was given with an ulterior motive than for a benefit that did not come with strings attached. Interestingly, however, ulterior and malicious motives do not always disqualify gratitude; some individuals are still grateful for a benefit regardless of a benefactor's motivation in conferring it, whereas other people rule out gratitude in these circumstances (Gulliford and Morgan 2016). One explanation for this difference is that some people may ascribe more value to the benefit itself than to the reasons behind it. However, it is also possible that some people may be more sensitive to what they perceive as ingratiation than others.

Even though appraisals of benefactors' intentions are clearly an important aspect of gratitude, in real life we can only ever impute motivations to a benefactor. It is perhaps only the fullness of time that reveals whether a benefit was given generously, or whether there were more complicated - and possibly manipulative reasons - as to why a favor or benefit was bestowed. It is difficult to disentangle whether a beneficiary's gratitude is therefore 'warranted' by a benefactor's apparently virtuous act, or whether the beneficiary might be justified in an assessment that they had been a victim of a benefactor's attempts at ingratiation. Perhaps only time will tell. As such, it is perhaps not surprising that gratitude is often characterized by mixed emotions.

Mixed emotions often derive from the sense of indebtedness that co-occurs with gratitude. Some argue that gratitude and indebtedness are two separate and distinguishable responses to a benefit, with gratitude engendering a purely positive response and indebtedness a negative one (Watkins et al. 2006). However, non-professionals do not seem to make this tight distinction, seeing gratitude as a phenomenon which they associate with both positive and negative features (Morgan et al. 2014). Moreover, correlations between gratitude and indebtedness in Watkins et al.'s own study (Watkins et al. 2006) suggest the two are not clearly distinguishable in practice.

This link between gratitude and negatively valenced outcomes has been supported by qualitative data. In response to statements about gratitude 'not being an entirely pleasant emotion', adult and adolescent participants frequently referenced feelings of indebtedness or obligation. Thus one clear reason for mixed emotions surrounding gratitude is the unpleasant feeling of needing to repay a benefit (Gulliford and Morgan 2018). Other themes that emerged included awkwardness, embarrassment or discomfort and guilt and, of particular interest here, the reference to benefactors' intentions.

One reason why people may be suspicious of a benefactor's motivation in bestowing a favor, gift or compliment could be that they suspect the benefactor is attempting to ingratiate themselves with the beneficiary or with other people, though not necessarily because the ulterior motive is to call in a corresponding favor later on (to make someone feel indebted). An ulterior or non-benevolent motive could take a number of forms. A malicious person could give a gift to anger or shame someone. Or, someone might do a favor or give a compliment to promote an impression of themselves as an agreeable, likeable and kind person. While some people give to others to ingratiate themselves, the same people (and others) might also give thanks for the same reason; namely, because the impression of oneself as a grateful person is likely to help to establish oneself in the good graces of other people and is generally perceived to be good for one's image.

Whilst previous work has highlighted that gratitude may not be as uncomplicatedly positive as many people have assumed, this paper goes deeper into the possible shadow side of gratitude, probing the relationship between gratitude and ingratiation (the deliberate attempt to establish oneself or someone else in the favor or good graces of another person). Both gratitude and ingratiation share a common root in the Latin 'grat' meaning 'favor'. Ingratiation is associated with a number of techniques, such as giving gifts and compliments and rendering favors to other people. Given that ingratiation involves material and non-material benefits like these, targets are likely to feel genuinely grateful for benefits they may not realize are freighted with a hidden agenda. In this way, 
ingratiators can exploit the predictable, grateful responses of others for their own ends.

Arguably, people who use gratitude in this manipulative way have a clear understanding of the dynamics of gratitude - how it 'works' and therefore how it can be exploited. It seems reasonable to postulate that these individuals might also realize the benefits of presenting themselves as grateful acknowledgers of benefits bestowed by others, in order to give a good impression of themselves to other people - and to keep more benefits coming. If gratitude is used in this way, it could rightly be designated an impression management strategy.

\section{Gratitude as a Possible Impression Management Strategy}

In a now classic study, Rind and Bordia (1995), reported that a server's addition of a hand-written 'thank you' to a restaurant bill increased tips by $11 \%$, relative to a control condition in which nothing was written on the tab. They proposed that impression-management theory offered an explanation as to why this minimally effortful strategy reaped rewards; 'According to impression-management theory, actors manipulate targets' impression of them to increase their influence over the targets for short- or long-terms gains' (Jones and Pittman 1980; Tedeschi and Riess 1981, cited in Rind and Bordia 1995, p. 746).

Impression management theory derives from Goffman's work on the presentation of the self (Goffman 1959) and postulates a number of strategies individuals use in an attempt to influence people's perceptions of them (Rosenfeld et al. 1995). Jones and Pittman (1980) identified five key impression-management tactics, including self-promotion (where people play up their abilities so as to be perceived as competent); exemplification (where individuals go above and beyond what is expected so as to appear dedicated); supplication (users of this strategy advertise their shortcomings so as to appear needy); intimidation (where people seek to come across as intimidating to have others perceive them as dangerous) and, importantly for the current paper, ingratiation (where individuals use compliments or perform favors in order to appear likeable). Additionally, expressions of gratitude can in themselves be used as an ingratiation strategy, as evidenced in Rind and Bordia's aforementioned study.

The line between a person being genuinely grateful and being disingenuously ingratiating may sometimes be hard to draw. However, in Rind and Bordia's (1995) study it seems pretty clear that the latter is in play; because it is surely the diners who should be thanking the server, not the other way around. The incongruity between who is thanking whom in this example is perhaps indicative of gratitude being deployed as a 'strategic move' rather than being expressed in a genuine way.
An alternative explanation for the tactic's success (in contrast to impression management) could be that writing 'thank you' on the bill sets up an expectation of a reward, as the researchers noted, leading to a self-fulfilling prophecy. However, the fact that earlier research (by Crano and Sivacek 1982 and Goldman et al. 1982) had demonstrated that expressing gratitude to targets (authors' own italics) increases the actors' influence over them, coupled with personal and anecdotal experiences, seems to favor the impressionmanagement explanation; we have all been 'played' at some point in our lives.

\section{The Roles of Self-Monitoring and Social Intelligence in Impression Management}

While there may be worthwhile returns to be reaped from ingratiation, it carries the risk of being exposed as an impression management strategy, and instead of being perceived as likeable (the desired impression sought) users may be perceived negatively as sycophantic. Turnley and Bolino (2001) examined how users of self-management strategies (including ingratiation) were able to achieve desired impressions while avoiding undesirable ones. They proposed that this was mediated by individuals' self-monitoring abilities.

The concept of self-monitoring was advanced by social psychologist, Mark Snyder (1974, 1979, 1987). It describes how individuals monitor and modify the way they present themselves to others both verbally and non-verbally. Since self-monitoring is construed as a personality trait, high and low self-monitors can be identified according to the degree to which they modify their expressive behavior and affective reactions in social situations. High self-monitors adjust their behaviour to enhance their self-presentation in a social setting, whereas low self-monitors act more spontaneously and do not consciously modify their behavior to present themselves in different ways in different social contexts. Self-monitoring can be measured at the trait level using the Self-Monitoring Scale (Snyder 1979; Lennox and Wolfe 1984).

Given the role of ingratiation in the impression management literature, it seems reasonable to hypothesize that a relationship might exist between gratitude and self-monitoring. More specifically, we propose that people who score high on a self-report test of their ability to modify their selfpresentation will report higher scores on a scale measuring multiple dimensions of gratitude. People who have the ability to modify the way they present themselves to others may be more aware of the effect gratitude might have on others through a keenly developed understanding of the complex social dynamics of gratitude.

As noted, a number of studies have shown that a range of appraisals underlie attributions of gratitude (Tesser et al. 1968; Wood et al. 2008b; Gulliford and Morgan 2016; Morgan et al. 2017). The ability to take these complex dynamics into 
consideration calls for highly developed social cognition, explaining age-related differences in understanding factors influencing attributions of gratitude (Morgan and Gulliford 2017). An individual who appreciates that people tend to take a gift's cost and benefactor's intentions and effort into consideration when making a grateful attribution, could use this knowledge to modify how generous they appear to others. For example, leaving a price-tag on a gift signals the cost to the recipient and could be used as an impression management strategy: 'See how generous I am!' This tactic is also likely to influence the beneficiary's gratitude, and, in turn, their future reciprocation to the benefactor. A complex knowledge of the dynamics of gratitude could therefore be used to ingratiate oneself with others, and might explain why some people are sceptical of the idea of gratitude as a virtue (see Carr 2016; Card 2016). It is possible these critics have encountered its (mis) use in the service of its vicious cousin, ingratiation. Given that understanding the complex dynamics of gratitude calls for highly developed skills in social cognition, it seems plausible to hypothesize that people who score high on measures of social intelligence would also be aware of the possible effects their gratitude might have on others, whether or not they decided to use this knowledge for their own advantage.

The idea of social intelligence is not new; Thorndike (1920) famously categorized intelligence into three 'types': abstract, mechanical and social intelligence, defining the latter as 'the ability to understand and manage men and women, boys and girls - to act wisely in human relations' (Thorndike 1920, cited in Kihlstrom and Cantor 2011). Landy (2005) contends that the publication of Thorndike's famous article in 'Harper's Magazine', as opposed to an academic journal, suggests the intention was to caution against narrow measurements of intelligence, rather than propose a new theory of intelligence, even if his contribution has subsequently been interpreted that way. There can be no doubt that the publication of this piece precipitated scholarly interest in the concept of social intelligence for several decades. Early theorists including Strang (1930), Vernon (1933), Wedeck (1947) and Wechsler (1958), characterized social intelligence (SI) as incorporating sensitivity to social cues and insight into the personalities and emotions of others in the social world. More recently, developmental psychologists, Greenspan and Love (1997) proposed SI to consist of social sensitivity, social insight and social communication. Measures of SI include the Tromsø social intelligence scale (Silvera et al. 2001), which tests an individual's social information processing, social skills and social awareness.

It is important, at this juncture to acknowledge that SI overlaps with a number of allied concepts. Lievens and Chan (2017) examined the commonalities and differences between practical intelligence, emotional intelligence and social intelligence. Emotional intelligence has risen to prominence in the last 30 years, enjoying a boost from Goleman's popular book of the same name (Goleman 1995), and is defined as 'the ability to monitor one's own and others' feelings, to discriminate among them, and to use this information to guide one's thinking and action' (Salovey and Mayer 1990, p. 189). On Salovey and Mayer's reading, EI is made up of four components: ability to perceive emotions in oneself and others; use of emotions in problem-solving; understanding emotions, and managing emotions in oneself and others.

Kihlstrom and Cantor (2011) argue that while SI and EI are not the same, there are clear family resemblances between them. Emotions are frequently evoked in social contexts, leading to an obvious overlap in when SI and EI might come into play. Landy (2005) goes as far as to suggest that EI has effectively replaced earlier work on SI, suggesting a virtual equivalence in the meaning of the terms. While this overwrites nuances between the concepts, it seems likely that the study of SI has been boosted by more recent interest in EI, as Kihlstrom and Cantor (2011) believe to be the case.

Research on the correlates and outcomes of EI, which has received most research interest in recent years may apply by extension to the other concepts we have identified as part of the 'nomological network' (social intelligence and social effectiveness). In a review of the construct, Mayer, Roberts and Barsade (2008, p. 525) summarize a number of positive outcomes associated with EI, including better social relationships for children and adults, more positive perceptions of high-EI individuals by others, better family and intimate relationships, better academic achievement, better working relationships and better psychological wellbeing. Given the overlap between the concepts of EI and SI we have discussed, we could perhaps expect SI to yield similar benefits, both intrapersonally and interpersonally.

\section{The Darker Side of Social and Emotional Intelligence}

Emotional Intelligence has more recently come under a harsher spotlight insofar as regulating the emotions of others may not always be done for the most benign of reasons (see Austin and O'Donnell 2013). Indeed, there could be a fine line between helping others to handle their emotions and manipulating others for self-interested motives.

This point is eloquently made by philosopher, David Carr (2000) who sounded a cautionary ethical note about EI when it started to gain traction in educational contexts:

'...from the ethical standpoint, it is not obvious that a person who has cultivated a precise knowledge of his own or other people's feelings and emotions, or who has learned to manage or control his or her own emotions should by this sole token be considered a morally better person than someone who has not ... Indeed, something not always clearly distinguishable from emotional intelligence - emotional cleverness or cunning - has often 
been used by political demagogues to further their own ends via the mass manipulation - even destruction - of others' (Carr 2000, p. 31).

Porter et al. (2011) reported that individuals higher in EI were able to produce more convincing deceptive displays of emotion for longer than people lower in EI, though they were no better at concealing genuinely felt emotions than people low in EI. Such dissimulation would be an asset for an ingratiating benefactor seeking to influence others by inauthentic displays of gratitude and of other emotions.

Nagler et al. (2014) report that narcissists and psychopaths use emotional intelligence skills for the emotional manipulation of others, while Kilduff et al. (2010) note that research on EI has 'disproportionately focused on prosocial outcomes and has neglected the possibility that individuals high in EI may use their skills to advance their own interests, even at the expense of others' (Kilduff et al. 2010, p. 129). Davis and Nichols (2016) review a number of studies which demonstrate that the construct of 'emotional intelligence' (EI) may have a 'dark' side, either intrapersonally or interpersonally. In the former case, EI may contribute to psychological illhealth (e.g. stress reactivity), whereas in the latter instance, EI may play a part in manipulative and antisocial behavior.

While the 'shadow side' of SI is under-explored it seems plausible (on the basis of the common ground linking SI and EI) to posit that SI might also have its shadier aspects. If SI can be defined as, '...one's ability to understand interpersonal situations and transactions and to use that understanding to assist one in achieving desired interpersonal outcomes...' (Greenspan and Love 1997, p. 311), it could also serve instrumentalist goals of getting what one wants from others, perhaps manipulatively or coercively.

In this connection, research has revealed links between social intelligence and interpersonal aggression. Loflin and Barry (2016) found that self-reported social intelligence (using the Tromsø Social Intelligence Scale) was associated with higher self-reported relational aggression in females. Kaukiainen et al. (1999) found that indirect aggression correlated positively and significantly with social intelligence in Finnish schoolchildren, while verbal and physical aggression had almost zero correlation with SI. The fact that indirect aggression seems to call for more social intelligence than direct forms of verbal of physical aggression is perhaps not surprising given the intent of indirect aggression to harm social relations. While social intelligence and empathy are correlated, it is empathy which determines whether social intelligence serves prosocial or antisocial ends (see Björkqvist et al. 2000).

Thus SI could have a dark side depending on the use to which this species of intelligence might be put. Cantor and Kihlstrom (1987) note that SI subsumes the metacognitive skills of self-monitoring and planning to maximize the efficacy of an individual's actions towards the pursuit of a goal - a pursuit which is 'not necessarily manipulative or conniving' (Cantor and Kihlstrom 1987, p. 175, author's italics). Such a quotation hints at a potentially less wholesome side to SI. Nancy Snow (2010) references the work of Robert Sternberg whose distinction between SI and wisdom hangs on the fact that the former is morally neutral, while the latter is not; 'SI can be applied to understanding and getting along with others, to any ends, for any purposes. Wisdom seeks out a good through a balancing of interests' (Sternberg 1998, p. 359, cited in Snow 2010).

Empirical evidence linking self-presentation, social intelligence and gratitude would buttress the argument that gratitude could be used as an impression management strategy. Here we document preliminary evidence from two studies that suggest that gratitude is associated with self-monitoring and social intelligence thereby paving the way for future explorations of gratitude versus ingratiation.

\section{Study 1}

Study 1 sought to explore whether the abovementioned conceptual links between gratitude and facets of impression management (i.e., self-monitoring and social intelligence) could be observed using well-validated psychometric scales designed to measure these constructs of interest.

\section{Participants}

Three-hundred-and-eleven participants from the UK took part in this study, of which 50\% were female. Ages ranged from 18 to 73 years ( $M=38$ years). $95 \%$ of respondents were either White-British, White-Irish or Other White Background. 48\% of the sample identified as Christian, 28\% as atheist and $12 \%$ as agnostic. Of those who identified with a religion, 22\% practiced this religion regularly. Participants were recruited via a crowd-sourcing website and paid $£ 1.50$ in return for completing the 15-min online questionnaire.

\section{Measures $^{1}$}

The Gratitude Questionnaire-6 (GQ6, McCullough et al. 2002). A 6-item measure gauged the frequency and intensity of participants' gratitude experience. Items are answered using a 7-point Likert scale ranging from $1=$ strongly disagree to $7=$ strongly agree. Good internal consistency and high testretest reliability has been consistently demonstrated (Wood et al. 2008a).

\footnotetext{
${ }^{1}$ It should be noted that additional outcomes measures were included as part of a larger research project but will not be discussed here for the sake of brevity.
} 
Multi-Component Gratitude Measure (MCGM, Morgan et al. 2017). Three subscales of the MCGM were utilized in this study to examine emotions, attitudes and behaviors relating to gratitude. Recent advancements in the measurement of gratitude have highlighted that gratitude is more than an emotion, as is measured by the GQ6 (Morgan et al. 2017); the MCGM offers a more comprehensive assessment of gratitude and has been shown to have incremental validity above and beyond the existing gratitude scales combined. However, given that this is a new measure, it is prudent to test this alongside the well-validated GQ6 measure described above.

The 6-item emotion subscale $(\alpha=.89)$ and 10-item attitude subscales $(\alpha=.83)$ are answered using a 7-point Likert scale ranging from $1=$ strongly disagree to $7=$ strongly agree. The 13-item behavior subscale ( $\alpha=.83$ ) is answered using a 7point Likert scale ranging from $1=$ never to $7=$ more than once a day. Example items include: "Thinking about all I have to be grateful for makes me feel happy" (Emotion item); "It is important to acknowledge the kindness of other people" (Attitude item) and "I go out of my way to thank others for their help" (Behavior item).

Self-monitoring scale (Lennox and Wolfe 1984). The 7item subscale 'ability to modify self-presentation' examined self-presentation $(\alpha=.77)$; this allowed for an examination of participants' perceived self-presentation abilities with respect to interpersonal interactions. Items are answered using 6-point Likert scale ranging from $0=$ certainly always false $-5=$ certainly always true. Example items include: 'I have the ability to control the way I come across to people, depending on the impression I wish to give them' and 'Even when it might be to my advantage, I have difficulty putting up a good front' (reverse scored).

Tromsø Social Intelligence Scale (TSIS, Silvera et al. 2001). The three subscales of the TSIS were used to measure three distinct facets of social intelligence: social skills $(\alpha=.85)$ social awareness $(\alpha=.72)$ and social information processing $(\alpha=.79)$. Each subscale is comprised of 7 items and are answered using a 7-point Likert scale ranging from $1=$ describes me very poorly to $7=$ describes me extremely well. Example items include: "I fit in easily in social situations" (Social Skills); "I find people unpredictable" (Social Awareness (reverse scored)); "I know how my actions will make others feel" (Social Information Processing).

\section{Procedure $^{2}$}

All self-report scales were administered via an online questionnaire. The order of the impression management scales

\footnotetext{
${ }^{2}$ All procedures performed in studies involving human participants were in accordance with the ethical standards of the institutional and/or national research committee and with the 1964 Helsinki declaration and its later amendments or comparable ethical standards. Informed consent was obtained from all individual participants included in the study.
}

was randomized but always followed the gratitude selfreport scales.

\section{Results}

As can be seen in Table 1, we observe small but significant correlations between the four scales of gratitude and the four dimensions associated with impression management (or, more specifically, self-monitoring and social intelligence). The positive direction of these correlations suggests that higher endorsements of gratitude experience are related to higher levels of self-monitoring and social intelligence.

These small but significant results are, unsurprisingly, mirrored in multiple linear regressions carried out to determine whether gratitude (experience) can predict variance in individuals' self-monitoring and social intelligence scores. To avoid multicollinearity effects, a composite gratitude score was created by combining $\mathrm{Z}$-scores for each of the gratitude scales to give one predictor variable. A two-step hierarchical linear regression $^{3}$ was carried out for each of the key outcome variables (self-monitoring, self-awareness, social skills, and social information processing). At the first step, the demographic variables of age, gender and practice religion were entered into the regression as these variables have been demonstrated to impact gratitude experience (McCullough et al. 2002; Morgan and Gulliford 2017; Morgan et al. 2017). A significant model emerged for social awareness only $(\mathrm{F}=3.65$, $p=.014$, adjusted $\mathrm{R}^{2}=.04$,), with gender as a significant predictor of variance in social awareness scores $(\beta=-.21$, $p<.01)$. At the second step, gratitude scores were entered, which resulted in a significant model for all outcome variables. Gratitude was able to account for an additional $11.5 \%$ of variance in self-monitoring scores $(\beta=.35, p<.001, \mathrm{~F}=$ $8.48, p=.000)$, an additional $10 \%$ of variance in social awareness scores $(\beta=.33, p<.001, \mathrm{~F}=611, p=.000)$, an additional $9.9 \%$ of variance in social skills $(\beta=.33, p<.001, \mathrm{~F}=6.00$, $p=.000)$, and an additional $11.4 \%$ of variance in social information processing scores $(\beta=.35, \mathrm{p}<.001, \mathrm{~F}=6.94$, $p=.000)$.

Whilst these results suggest that gratitude and various facets of impression management which could be linked to ingratiation appear to be related to one another, they do little to decipher the direction of these relationships. It is possible that greater experience and endorsements of gratitude lead to heightened self-monitoring and social intelligence, but it is equally probable that individuals who are socially aware of themselves and others are more likely to recognize grateful acts. This thereby highlights possible positive and dark sides in the links between gratitude and impression management -

\footnotetext{
${ }^{3}$ Assumptions for parametric testing are met, all variables were normally distributed and all Durbin Watson scores fell within the acceptable parameters of 1 and 3 (Durbin and Watson 1951).
} 
Table 1 Correlational matrix demonstrating the relationships between all constructs of interest

\begin{tabular}{lllllllll}
\hline & 1 & 2 & 3 & 4 & 5 & 6 & 7 & 8 \\
\hline 1 MCGM, emotion subscale score & 1 & $.33^{* *}$ & $.47^{* *}$ & $.71^{* *}$ & $.29^{* *}$ & $.32^{* *}$ & $.30^{* *}$ & $.20^{* *}$ \\
2 MCGM, attitude subscale score & & 1 & $.36^{* *}$ & $.41^{* *}$ & $.17^{* *}$ & .10 & $.18^{* *}$ & $.23^{* *}$ \\
3MCGM, behavior subscale score & & & 1 & $.58^{* *}$ & $.20^{* *}$ & $.24^{* *}$ & $.22^{* *}$ & $.16^{* *}$ \\
4 GQ6 score & & & 1 & $.27^{* *}$ & $.33^{* *}$ & $.28^{* *}$ & $.20^{* *}$ \\
5 Self-monitoring score & & & & 1 & $.50^{* *}$ & $.50^{* *}$ & $.29^{* *}$ \\
6 Social information processing score & & & & & 1 & $.42^{* *}$ & $.22^{* *}$ \\
7 Social skills score & & & & & & 1 & $.39^{* *}$ \\
8 Social awareness score & & & & & & & 1 \\
\hline
\end{tabular}

** $p<.001$, Pearson Correlation $(N=311)$ somewhat akin to 'the Jekyll and Hyde of emotional intelligence' where EI is linked to both prosocial and interpersonally deviant behaviors (Côté et al. 2011, p. 1073).

\section{Study 2}

In the introduction we highlighted how gratitude necessitates skills in social cognition - understanding the dynamics of when gratitude is due calls for an appreciation of the benefactor's intentions and motivations as well as the cost and effort incurred in the bestowal of a benefit (as neatly described in Wood et al.'s (2008b) socio-cognitive model of gratitude). This could also suggest, therefore, that an enhanced focus on gratitude (which requires the heightened use of social cognition) might also lead to increases in social intelligence: this would provide more convincing evidence that these concepts are indeed linked. To this end, Study 2 explored whether practicing gratitude can lead to changes in impression management skills, specifically social intelligence, through the design and delivery of a gratitude intervention.

Gratitude interventions, originally adopted within the field of positive psychology but now commonplace in wellbeing practices, often involve focusing on and recalling one's benefits which makes for a quick and easy way of enhancing gratitude that is typically considered enjoyable for the participant (Davis et al. 2016). In the current study, participants were invited to 'count their blessings' every day for 2 weeks, with pre- and post-intervention tests used to gauge changes in levels of gratitude and social intelligence during this period. These scores were compared to those of a control group who were practicing pride in place of gratitude (that is, participants recalled and wrote down three things they were proud of in place of three things they were grateful for). A comparison of pride exercises was chosen in light of previous criticisms of comparing gratitude with neutral or affect-decreasing conditions. Both pride and gratitude have been associated with gains in positive affect and, therefore, this negates the argument that any gains in the gratitude condition are simply attributable to increases in positive affect across the two testing points (see Watkins et al. 2015).

It was hypothesized that practicing gratitude (through counting blessings) would function to increase individuals' levels of gratitude post-intervention. Furthermore, due to the enhanced use of social cognitions associated with gratitude practice, it was hypothesized that practicing gratitude would function to increase individuals' self-reported levels of social intelligence post-intervention, as compared to the pride control condition.

\section{Participants}

Fifty-two participants were recruited to this two-week intervention and randomly allocated to one of the two conditions. Due to attrition over the two-week period, only 40 participants completed the post-intervention questionnaire. Of these, 36 participants were included in the analysis stage with four participants excluded on the basis of outlying and missing data. ${ }^{4}$ This left 18 participants in each condition. In the Gratitude condition, 17 participants were female and ages ranged from 18 to $60(\mathrm{M}=31, \mathrm{SD}=14)$. In the Pride control condition, 12 were female and ages ranged from 18 to $51(\mathrm{M}=27, \mathrm{SD}=9)$.

Participants were recruited via opportunistic sampling through the use of social media and advertisements at the University of Worcester. The majority of participants were undergraduate students who received course credit in exchange for participation.

\section{Measures $^{5}$}

Multi-Component Gratitude Measure (MCGM, Morgan et al. 2017). The Emotion and Behaviour subscales of the MCGM

\footnotetext{
${ }^{4}$ Outlying data refers to levels of positive and negative affect which fall above 2 SDs of the mean.

${ }^{5}$ It should be noted that additional outcomes measures were included as part of a larger research project but will not be discussed here for the sake of brevity.
} 
were used to gauge gratitude-related feelings and behaviours (see Study 1).

The Gratitude Resentment and Appreciate Scale, Short Version (GRAT-S, Watkins et al. 2003). The Appreciation of Others subscale of the GRAT-S was also included as this specifically examines the interpersonal nature of gratitude and allows for a more in-depth exploration of gratitude directed towards others.

Responses to these four items are rated on a 9-point Likert scale ranging from $1=$ strongly disagree to $9=$ strongly agree $(\alpha=.76)$.

Tromsø Social Intelligence Scale (TSIS, Silvera et al. 2001). Details as per Study 1.

Positive Affect Negative Affect Scale (PANAS, Watson and Clark 1988). Given the well-established relationship between wellbeing and gratitude, this scale was included to establish participants' levels of positive and negative affect and used as a screening variable (Wood et al. 2010). Participants' baseline levels of wellbeing can impact their ability to engage with gratitude interventions and, arguably, particularly low levels of wellbeing pre-intervention can inhibit engagement in gratitude (and pride) interventions. Participants were provided with 10 positive and 10 negative feelings and asked to what extent they had felt that way in the past week (e.g., Interested, Excited; Distressed, Ashamed). Responses were rated on a 5point Likert scale ranging from $1=$ Not at all to $5=$ Extremely.

\section{Procedure $^{6}$}

Participants first completed all scales before starting the intervention: these measures were collected via an online questionnaire. After completing these pre-intervention scales, participants were invited to either write down three things that they were grateful for that day (gratitude condition) or write down three things that they were proud of that day (pride condition).

In the gratitude condition, participants were provided with an interpersonal definition of gratitude and examples to prompt observations of gratitude that include a particular benefactor: 'Gratitude is an emotion expressed in response to kind actions from another. Please write down three things that you are grateful for today. For example, I am grateful for a gift received from another person, I am grateful for my colleague making me a cup of tea, I am grateful for my friend helping me with my essay.' In the pride condition, participants were given a definition and examples that highlighted its intrapersonal nature: 'Pride is an inwardly directed emotion in response to personal accomplishments or something that you are personally pleased with. Please write down three things that you are

\footnotetext{
${ }^{6}$ All procedures performed in studies involving human participants were in accordance with the ethical standards of the institutional and/or national research committee and with the 1964 Helsinki declaration and its later amendments or comparable ethical standards. Informed consent was obtained from all individual participants included in the study.
}

proud of today. For example, I am proud that I made progress on an assignment, I am proud that I attended the gym, I am proud that I did the housework.'

Participants were instructed to enter an online record of these observations and repeat this process daily for 2 weeks. The researchers provided reminders every other day to prompt participants into keeping these daily records. At the end of the two-week intervention, participants were asked to complete the same measures of gratitude, affect and social intelligence as to provide post-intervention scores.

\section{Results}

As can be seen in Table 2, mean gratitude scores (as measured by the emotion and behavior subscales of the MCGM and the simple appreciation and appreciation of others subscales of the GRAT-S) increased following the 2-week gratitude intervention. Table 2 also illustrates increases in social intelligence (as measured by social awareness, social skills and social information processing scales) from pre- to post-intervention. These differences are confined to the gratitude intervention, with the pride intervention leading to decreases in (self-reported) levels of social awareness and social information processing.

Composite scores for gratitude ${ }^{7}$ and social intelligence were calculated from combining the subscales, and a repeated measures ANOVA was conducted with pre- and post- scores for gratitude and social intelligence as the within-subjects variables and condition as a between-subjects factor. The results demonstrated that gratitude significantly increased following the gratitude intervention $\left(\mathrm{F}(1,34)=1842.20, p=.000, \eta_{\mathbf{p}}{ }^{2}=.98\right)$. A non-significant interaction between gratitude and condition demonstrates that this increase in gratitude was no stronger in the experimental condition than the pride control intervention, contradicting our earlier hypothesis $(\mathrm{F}(1,34)=3.30, p=.078$, $\left.\eta_{\mathbf{p}}{ }^{2}=.09\right)$. However, a significant interaction between social intelligence scores and condition demonstrated that, as predicted, social intelligence increased from pre- to post-intervention in the gratitude condition, but not in the pride condition ( $\mathrm{F}(1$, $34)=10.19, p=.003, \eta_{\mathbf{p}}^{2}=.23$ ), see Fig. 1 .

\section{Discussion}

The preliminary findings from Studies 1 and 2 indicate that a relationship between gratitude, self-monitoring and social intelligence does exist and that practicing gratitude could lead to gains in social intelligence. The function of this relationship, however, requires further questioning as these preliminary findings cannot tease apart how gratitude and social intelligence gains will be put to use.

\footnotetext{
${ }^{7}$ Given the different response sets used to report gratitude in the GRAT-S and MCGM, the composite score for gratitude was calculated using $\mathrm{z}$ scores.
} 
Table 2 Mean pre- and post-intervention, across all subscales and conditions

\begin{tabular}{|c|c|c|c|c|}
\hline \multirow{2}{*}{$\begin{array}{l}\text { Condition } \\
\text { (Sub)Scale: }\end{array}$} & \multicolumn{2}{|l|}{ Gratitude } & \multicolumn{2}{|l|}{ Pride } \\
\hline & $\begin{array}{l}\text { Pre mean } \\
\text { score (SD) }\end{array}$ & $\begin{array}{l}\text { Post mean } \\
\text { score (SD) }\end{array}$ & $\begin{array}{l}\text { Pre mean } \\
\text { score (SD) }\end{array}$ & $\begin{array}{l}\text { Post mean } \\
\text { score (SD) }\end{array}$ \\
\hline GRAT-S appreciation of others & $6.23(2.2)$ & $7.69(1.6)$ & $7.00(1.0)$ & $6.76(1.2)$ \\
\hline MCGM emotion & $5.55(1.8)$ & $6.51(.99)$ & $5.56(.78)$ & $5.75(1.0)$ \\
\hline MCGM behaviour & $4.76(1.1)$ & $5.23(.67)$ & $4.87(.51)$ & $4.81(.56)$ \\
\hline Social awareness & $4.63(1.2)$ & $5.28(1.2)$ & $5.05(.79)$ & $4.94(1.0)$ \\
\hline Social skills & $4.26(.66)$ & $4.36(.82)$ & $4.43(.62)$ & $4.50(.65)$ \\
\hline Social information processing & $5.15(.76)$ & $5.25(.76)$ & $4.90(.79)$ & $4.80(.90)$ \\
\hline Composite gratitude score ${ }^{\mathrm{a}}$ & .06 & .31 & -.14 & -.44 \\
\hline Composite social intelligence score & 4.69 & 4.95 & 4.78 & 4.74 \\
\hline
\end{tabular}

${ }^{\mathrm{a}}$ The composite gratitude score is calculated from standardized variables
It is likely that for some (or even many) individuals, practicing gratitude focuses our attention on the benefits received and the role that others play in conveying these benefits. Therefore, this relationship between gratitude and social intelligence could be a positive one that demonstrates a greater awareness of sociality and heightened social bonds. Indeed, research has demonstrated that gratitude can function to build and maintain social relationships and lead to prosocial behaviors (Bartlett et al. 2012; Algoe et al. 2008).

Having said this, however, we have highlighted above a potential shadow side of gratitude, self-monitoring and social intelligence. We suggested that for some individuals high in social intelligence and self-monitoring (the latter of which manifests in the higher-order category of social intelligence), displays of gratitude could be used to advance self-interested goals. In such cases, gratitude's vicious cousin, ingratiation could be at play. Given that EI has been shown to be related to manipulation and antisocial behavior (Davis and Nichols 2016), and the research showing the role of SI in relational and indirect aggression (Loflin and Barry 2016; Björkqvist et al. 2000; Kaukiainen et al. 1999), the suggestion that SI (and the self-monitoring abilities it encompasses) might also relate to similar outcomes is perhaps not as outlandish as it may appear to researchers keen to advocate the sunnier side of gratitude. In this connection, further research using scales assessing manipulative interpersonal behavior, such as the Managing the Emotions of Others Scale (MEOS) (Austin and O'Donnell (2013)) and the Political Skill Inventory (PSI) (Ferris et al. (2005)) could prove helpful in teasing out non-pro-social gratitude.

As noted above, the positive psychological literature is replete with the intrapersonal and interpersonal benefits of gratitude. As such, there might be some resistance towards examining the 'shadow side' of this construct. It will be recalled that Watkins et al. (2006) sought to draw an unrealistically tight distinction between gratitude and indebtedness, characterizing the former as positive and the latter as negative. It seems that psychologists may have had a blind spot with regard to seeing the potentially darker side of gratitude. This is rather surprising, given the everyday experience of its vicious cousin, ingratiation, in our social lives. Gratitude has not yet been studied in relation to emotional manipulation even though it so clearly involves being able to understand the emotions of the self and others- an ability which could be put to both otherserving and self-serving ends.

In Study 1 a positive relationship between four gratitude scales and self-monitoring, social information processing, social skills and social awareness (three subscales of SI) was
Fig. 1 Social Intelligence scores before and after the gratitude and pride interventions

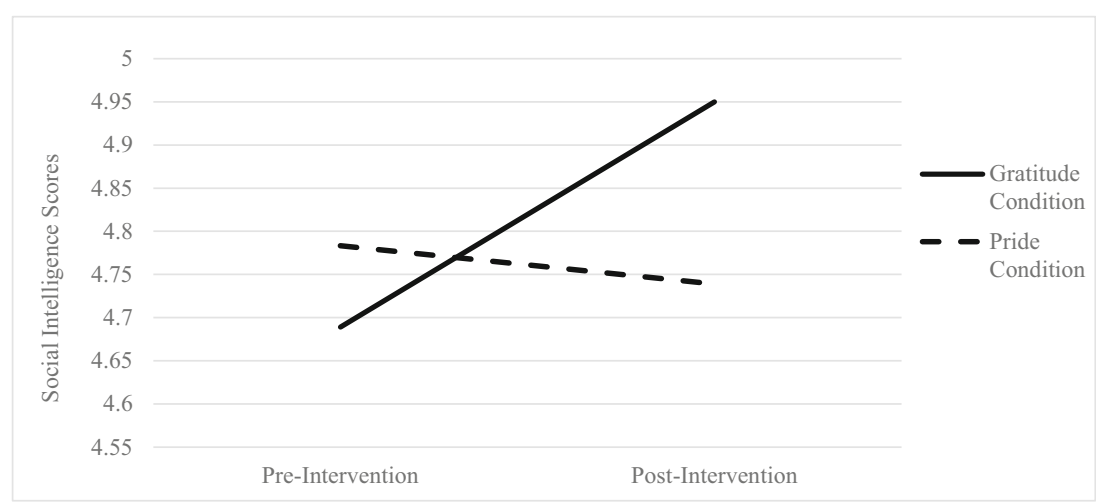


found. Gratitude is linked to self-monitoring and social intelligence skills. Resonating with previous research on the role of gratitude in building social bonds (Bartlett et al. 2012; Algoe et al. 2008), Study 2 showed that gratitude seemed to be particularly adept at increasing social awareness, which showed statistically significant changes post-intervention. This drove the overall finding that SI increased significantly at post intervention in the gratitude condition in comparison with the pride condition.

While Study 2 demonstrates that gratitude increases SI, the crucial question is: to what end? In and of itself, greater social intelligence could result in a virtuous or vicious cycle. Some people might use the increased social intelligence gained from a gratitude intervention to help build social bonds, benignly recognizing and reciprocating benefits received from others. On the other hand, others might use the increased social awareness and greater understanding of the dynamics of gratitude to ingratiate themselves with others for their own gain.

It is worth noting that the studies presented here have been characterized as providing preliminary data on the links between gratitude, self-monitoring and social intelligence, and these studies are not without their limitations. Whilst Study 1 involved a large and representative sample, the data collected is correlational in nature and provides little information on how the links between gratitude and facets of impression management serve to function. Study 2 attempted to broach this gap with an experimental study that sought to enhance individual's levels of gratitude over a 2week period and observe any associated changes in social intelligence. The $23 \%$ attrition rate and missing data postintervention left only 36 participants included in analysis, thereby affecting the power of the repeated measures ANOVA, and it should be borne in mind that the sample was predominantly female (particularly in the gratitude condition). Previous studies using the Tromsø Social Intelligence Scale have not demonstrated gender differences in responses (Silvera et al. 2001; Loflin and Barry 2016), however, researchers have noted that females typically selfreport higher levels of social skills (Petrides and Furnham 2000). Further to this, females tend to self-report higher levels of gratitude and have demonstrated a greater concern about connectedness to others (Crick and Grotpeter 1995; Morgan et al. 2017). Together these findings raise issues as to whether this increase in social intelligence is exaggerated based on the sample demographics; further research should certainly examine whether this link between gratitude and impression management can be replicated in larger and more diverse samples and it is recommended that attention is paid to possible gender-based differences.

In order to probe the potentially 'dark side' of gratitude further, one would need to examine the ends to which increased gratitude and the social awareness that accompanies it might be put. For example, if some of the waiting staff in Rind and Bordia's (1995) study had received the gratitude intervention described in Study 2, would they have been any more likely to have used the tip tactic of writing 'thank you' on the bill than waiting staff who had not participated in such an intervention? Such a finding would suggest that the direct promotion of gratitude (and the concomitant increase in social awareness) could result in a greater likelihood of using ingratiating tactics - a method which could be adapted for the purposes of an experiment.

Future work could also examine the associations of 'nonpro-social gratitude' with relevant personality traits, for example, honesty-humility (Ashton and Lee 2007), the Dark Triad (Paulhus and Williams 2002) and scales assessing manipulative interpersonal behaviour (Austin and O'Donnell 2013; Ferris et al. 2005). As evident above, much inspiration for furthering this exploration of what constitutes gratitude versus ingratiation can be gleaned from the work on the dark side of EI. Côté et al. (2011), for instance, showed that within occupational settings there was evidence that EI could be used negatively to manipulate others in the workplace. Similar manipulations could be expected with regard to gratitude; previous research has demonstrated that endorsements of gratitude within the workplace are positively related with job satisfaction (Waters 2012), however, this exploration of 'institutionalized gratitude' only explored the role of gratitude through a positive lens and no questions about the potential misuse of gratitude were discussed. A savvy and socially intelligent manager might seek to use expressions of gratitude as a motivational tool for their own gains and simple correlational relationships can only glean so much here.

Certainly, however, the manipulative tactics postulated here would not be employed by all individuals and certain dispositions and traits (e.g. the Dark Triad) would likely account for some variance in such behavior. Austin et al. (2014) found that although EI correlates negatively with the tendency to worsen others' moods in general, this relationship was moderated by agreeableness, with low agreeableness producing a much weaker negative relationship. Thus the way in which an individual with high levels of EI might regulate the moods of others depends on facets of personality. Again, this too might be true in the case of gratitude with key dispositional variables separating out gratitude from ingratiation. The development of a scale measuring non-prosocial gratitude specifically, could be helpful in examining this further in future studies.

It appears, therefore, that many questions are still unanswered about gratitude in terms of its prosocial nature. In real life the line between genuine gratitude and an ingratiating display is hard to draw and often difficult to call. It is hoped that the current study has at least raised the possibility that gratitude and the increased social awareness it engenders, might not exclusively be put to virtuous or prosocial ends; in 
the wrong hands gratitude might not be as 'quintessentially positive' as it may at first appear

Open Access This article is distributed under the terms of the Creative Commons Attribution 4.0 International License (http:// creativecommons.org/licenses/by/4.0/), which permits unrestricted use, distribution, and reproduction in any medium, provided you give appropriate credit to the original author(s) and the source, provide a link to the Creative Commons license, and indicate if changes were made.

\section{References}

Algoe, S. B., Haidt, J., \& Gable, S. L. (2008). Beyond reciprocity: Gratitude and relationships in everyday life. Emotion, 8, 425-429.

Ashton, M. C., \& Lee, K. (2007). Empirical, theoretical and practical advantages of the HEXACO model of personality structure. Personality and Social Psychology Review, 11, 150-166.

Austin, E. J., \& O'Donnell, M. M. (2013). Development and preliminary validation of a scale to assess managing the emotions of others. Personality and Individual Differences, 55(7), 834-839.

Austin, E. J., Saklofske, D. H., Smith, M., \& Tohver, G. (2014). Associations of the managing the emotions of others (MEOS) scale with personality, the Dark Triad and trait EI. Personality and Individual Differences, 65, 8-13.

Bartlett, M. Y., \& DeSteno, D. (2006). Gratitude and prosocial behavior: Helping when it costs you. Psychological Science, 17(4), 319-325.

Bartlett, M., Condon, P., Cruz, J., Baumann, J., \& DeSteno, D. (2012). Gratitude: Prompting behaviors that build relationships. Cognition and Emotion, 26, 2-13.

Barton, A. W., Futris, T. G., \& Nielsen, R. B. (2015). Linking marital distress to marital quality: The intermediary roles of demand/ withdraw and spousal gratitude expressions. Personal Relationships, 22, 536-549.

Björkqvist, K., Österman, K., \& Kaukiainen, A. (2000). Social intelligence - empathy = aggression? Aggression and Violent Behavior, 5(2), 191-200.

Cantor, N., \& Kihlstrom, J. F. (1987). Personality and social intelligence. Englewood Cliffs: Prentice Hall.

Card, C. (2016). Gratitude to the decent rescuer. In D. Carr (Ed.), Gratitude: An interdisciplinary approach (pp. 99-111). London: Routledge.

Carr, D. (2000). Emotional intelligence, PSE and self-esteem: A cautionary note. Pastoral Care in Education, 18, 27-33.

Carr, D. (2016). Gratitude: An educational postscript. In D. Carr (Ed.), Gratitude: An interdisciplinary approach (pp. 229-334). London: Routledge.

Côté, S., DeCelles, K. A., McCarthy, J. M., Van Kleef, G. A., \& Hideg, I. (2011). The Jekyll and Hyde of emotional intelligence emotionregulation knowledge facilitates prosocial and interpersonally deviant behavior. Psychological Science, 22, 1073-1080.

Crano, W. D., \& Sivacek, J. (1982). Social reinforcement, self-attribution, and the foot-in-the-door phenomenon. Social Cognition, 1, 110-125.

Crick, N. R., \& Grotpeter, J. K. (1995). Relational aggression, gender, and social-psychological adjustment. Child Development, 66(3), 710-722.

Davis, S. K., \& Nichols, R. (2016). Does emotional intelligence have a "dark" side? A review of the literature. Frontiers in Psychology, 7, Article 1316, 1-10.

Davis, D. E., Choe, E., Meyers, J., Wade, N., Varjas, K., Gifford, A., Quinn, A., Hook, J. N., van Tongeren, D. R., Griffin, B. J., \& Worthington, E. L., Jr. (2016). Thankful for the little things: A meta-analysis of gratitude interventions. Journal of Counseling Psychology, 63(1), 20-31.

Durbin, J., \& Watson, G. S. (1951). Testing for serial correlation in least squares regression. II. Biometrika, 38(1/2), 159-177.
Emmons, R. A., \& McCullough, M. E. (2003). Counting blessings versus burdens: An experimental investigation of gratitude and subjective well-being in daily life. Journal of Personality and Social Psychology, 84, 377-389.

Ferris, G. R., Treadway, D. C., Kolodinsky, R. W., Hochwarter, W. A., Kacmar, C. J., Douglas, C., \& Frink, D. D. (2005). Development and validation of the political skill inventory. Journal of Management, $31(1), 126-152$.

Geraghty, A. W. A., Wood, A. M., \& Hyland, M. E. (2010a). Dissociating the facets of hope: Agency and pathways predict dropout from unguided self-help therapy in opposite directions. Journal of Research in Personality, 44, 155-158. 5.

Geraghty, A. W. A., Wood, A. M., \& Hyland, M. E. (2010b). Attrition from self-directed interventions: Investigating the relationship between psychological predictors, intervention content and dropout from a body dissatisfaction intervention. Social Science and Medicine, 71, 30-37.

Goffman, E. (1959). The presentation of self in everyday life. New York: Doubleday.

Goldman, M., Seever, M., \& Seever, M. (1982). Social labelling and the foot-in-the-door effect. Journal of Social Psychology, 117, 19-23.

Goleman, D. (1995). Emotional intelligence. New York: Bantam Books, Inc.

Grant, A. M., \& Gino, F. (2010). A little thanks goes a long way: Explaining why gratitude expressions motivate prosocial behavior. Journal of Personality and Social Psychology, 98(6), 946-955.

Greenspan, S., \& Love, P. F. (1997). Social intelligence and development disorder: Mental retardation, learning disabilities and autism. In W. E. E. MacLean (Ed.), Handbook of mental deficiency: Psychological theory and research (3rd ed., pp. 311-342). Mahwah: Erlbaum.

Gulliford, L., \& Morgan, B. (2016). An empirical exploration of the normative dimensions of gratitude. In D. Carr (Ed.), Gratitude: An interdisciplinary approach. London: Routledge.

Gulliford, L., \& Morgan, B. (2018). The meaning and valence of gratitude in positive psychology. In N. Brown, T. Lomas, \& F. Eiroa-Orosa (Eds.), Critical positive psychology. London: Taylor \& Francis.

Jones, E. E., \& Pittman, T. S. (1980). Toward a general theory of strategic self-presentation. In J. Suls (Ed.), Psychological perspectives of the self (pp. 231-262). Hillsdale: Lawrence Erlbaum.

Joseph, D. L., \& Newman, D. A. (2010). Emotional intelligence: An integrative meta-analysis and cascading model. Journal of Applied Psychology, 95, 54-78.

Kaukiainen, A., Björkqvist, K., Lagerspetz, K., Österman, K., Salmivalli, C., Rothberg, S., \& Ahlbom, A. (1999). The relationships between social intelligence, empathy, and three types of aggression. Aggressive Behavior, 25(2), 81-89.

Kihlstrom, J. F., \& Cantor, N. (2011). Social intelligence. In R. J. Sternberg \& S. B. Kaufman (Eds.), The Cambridge handbook of intelligence. Cambridge: CUP.

Kilduff, M., Chiaburu, D. S., \& Menges, J. I. (2010). Strategic use of emotional intelligence in organizational settings: Exploring the dark side. Research in Organizational Behavior, 30, 129-152.

Kruse, E., Chancellor, J., Ruberton, P. M., \& Lyubomirsky, S. (2014). An upward spiral between gratitude and humility. Social Psychological and Personality Science, 5(7), 805-814.

Landy, F. J. (2005). Some historical and scientific issues related to research on emotional intelligence. Journal of Organizational Behavior, 26, 411-424.

Lennox, R. D., \& Wolfe, R. N. (1984). Revision of the self-monitoring scale. Journal of Personality and Social Psychology, 46, 1349-1364.

Lievens, F. R., \& Chan, D. (2017). Practical intelligence, emotional intelligence, and social intelligence. In Handbook of employee selection (pp. 342-364). New York: Routledge.

Loflin, D. C., \& Barry, C. T. (2016). 'You can't sit with us: 'Gender and the differential roles of social intelligence and peer status in adolescent relational aggression. Personality and Individual Differences, 91, 22-26. 
Martins, A., Ramalho, N., \& Morin, E. (2010). A comprehensive metaanalysis of the relationship between emotional intelligence and health. Personality and Individual Differences, 49, 554-564.

Mayer, J. D., Roberts, R. D., \& Barsade, S. G. (2008). Human abilities: Emotional intelligence. Annual Review of Psychology, 59, 507-536.

McCullough, M. E., Emmons, R. A., \& Tsang, J. (2002). The grateful disposition: A conceptual and empirical topography. Journal of Personality and Social Psychology, 82, 112-127.

McCullough, M. E., Kilpatrick, S. D., Emmons, R. A., \& Larson, D. B. (2001). Is gratitude a moral affect? Psychological Bulletin, 127(2), 249-266.

McCullough, M. E., Kimeldorf, M. B., \& Cohen, A. D. (2008). An adaptation for altruism: The social causes, social effects, and social evolution of gratitude. Current Directions in Psychological Science, 17(4), 281-285.

Morgan, B., \& Gulliford, L. (2017). Assessing influences on gratitude experience: Age-related differences in how gratitude is understood and experienced. In J. Tudge \& L. Frietas (Eds.), Developing gratitude. Cambridge: CUP.

Morgan, B., Gulliford, L., \& Kristjansson, K. (2014). Gratitude in the UK: A new prototype analysis and a cross-cultural comparison. The Journal of Positive Psychology, 9(4), 291-294.

Morgan, B., Gulliford, L., \& Kristjánsson, K. (2017). A new approach to examining moral virtues: The multi-component gratitude measure. Personality and Individual Differences, 107, 179-189.

Nagler, U. K. J., Reiter, K. J., Furtner, M. R., \& Rauthmann, J. F. (2014). Is there a 'dark intelligence'? Emotional intelligence is used by dark personalities to emotionally manipulate others. Personality and Individual Differences, 65, 47-52.

Naito, T., Wangwan, J., \& Tani, M. (2005). Gratitude in university students in Japan and Thailand. Journal of Cross-Cultural Psychology, $36(2), 247-263$.

Nowak, M. A., \& Roch, S. (2007). Upstream reciprocity and the evolution of gratitude. Proceedings of the Royal Society Biological Sciences, 274, 604-609.

Paulhus, D. L., \& Williams, K. M. (2002). The dark triad of personality: Narcissism, Machiavellianism, and psychopathy, Journal of Research in Personality, 36(6), 556-563.

Petrides, K. V., \& Furnham, A. (2000). Gender differences in measured and self-estimated trait emotional intelligence. Sex Roles, 42(5-6), 449-461.

Porter, S., ten Brinke, L., Baker, A., \& Wallace, B. (2011). Would I lie to you? "Leakage" in deceptive facial expressions relates to psychopathy and emotional intelligence. Personality and Individual Differences, 51, 133-137.

Rind, B., \& Bordia, P. (1995). Effect of server's "thank you" and personalization on restaurant tipping. Journal of Applied Social Psychology, 25, 745-751.

Rosenfeld, P. R., Giacalone, R. A., \& Riordan, C. A. (1995). Impression management in organizations: Theory, measurement and practice. New York: Routledge.

Salovey, P., \& Mayer, J. D. (1990). Emotional intelligence. Imagination, Cognition and Personality, 9, 185-211.

Silvera, D., Martinussen, M., \& Dahl, T. I. (2001). The Tromsø social intelligence scale: A self-report measure of social intelligence. Scandinavian Journal of Psychology, 42, 313-319.

Snow, N. (2010). Virtue as social intelligence. London: Routledge.

Snyder, M. (1974). Self-monitoring of expressive behavior. Journal of Personality and Social Psychology, 30(4), 526-537.

Snyder, M. (1979). Self-monitoring processes. Advances in Experimental Social Psychology, 12, 85-128.

Snyder, M. (1987). A series of books in psychology. Public appearances, private realities: The psychology of self-monitoring. New York: W H Freeman/Times Books/ Henry Holt \& Co.
Sternberg, R. J. (1998). A balance theory of wisdom. Review of General Psychology, 2(4), 347-365.

Sternberg, R. J., \& Wagner, R. K. (1986). Practical intelligence: Nature and origins of competence in the everyday world. Cambridge: CUP.

Strang, R. (1930). Measures of social intelligence. American Journal of Sociology, 36, 263-269.

Tedeschi, J. T., \& Riess, M. (1981). Identities, the phenomenal self, and laboratory research. In J. T. Tedeschi (Ed.), Impression management theory and social psychological research (pp. 3-22). New York: Academic.

Tesser, A., Gatewood, R., \& Driver, M. (1968). Some determinants of gratitude. Journal of Personality and Social Psychology, 9, 233-236.

Thorndike, E. L. (1920). Intelligence and its use. Harper's Magazine, 140, 227-235.

Tsang, J. A. (2006). Gratitude and prosocial behaviour: An experimental test of gratitude. Cognition \& Emotion, 20(1), 138-148.

Turnley, W. H., \& Bolino, M. C. (2001). Achieving desired images while avoiding undesired images: Exploring the role of self-monitoring in impression management. Journal of Applied Psychology, 86, 351-360.

Vernon, P. E. (1933). Some characteristics of the good judge of personality. Journal of Social Psychology, 4, 42-57.

Waters, L. (2012). Predicting job satisfaction: Contributions of individual gratitude and institutionalized gratitude. Psychology, 3(12), 1174-1176.

Watkins, P. C., Scheer, J., Ovnicek, M., \& Kolts, R. L. (2006). The debt of gratitude: Dissociating gratitude and indebtedness. Cognition and Emotion, 20, 217-241.

Watkins, P. C., Uhder, J., \& Pichinevskiy, S. (2015). Grateful recounting enhances subjective well-being: The importance of grateful processing. The Journal of Positive Psychology, 10(2), 91-98.

Watkins, P. C., Woodward, K., Stone, T., \& Kolts, R. L. (2003). Gratitude and happiness: Development of a measure of gratitude, and relationships with subjective well-being. Social Behavior and Personality, 31(5), 431-452.

Watson, D., \& Clark, L. A. (1988). Development and validation of brief measures of positive and negative affect: The PANAS scales. Journal of Personality and Social Psychology, 54(6), 1063-1070.

Wechsler, D. (1958). The measurement and appraisal of adult intelligence (4th ed.). Baltimore: Williams and Wilkins.

Wedeck, J. (1947). The relationship between personality and psychological ability. British Journal of Psychology, 36, 133-151.

Wood, A. M., Maltby, J., Gillett, R., Linley, P. A., \& Joseph, S. (2008a). The role of gratitude in the development of social support, stress, and depression: Two longitudinal studies. Journal of Research in Personality, 42, 854-871.

Wood, A. M., Maltby, J., Stewart, N., Linley, P. A., \& Joseph, S. (2008b). A social-cognitive model of trait and state levels of gratitude. Emotion, 8, 281-290.

Wood, A. M., Joseph, S., Lloyd, J., \& Atkins, S. (2009). Gratitude influences sleep through the mechanism of pre-sleep cognitions. Journal of Psychosomatic Research, 66(1), 43-48.

Wood, A. M., Froh, J. J., \& Geraghty, A. W. (2010). Gratitude and wellbeing: A review and theoretical integration. Clinical Psychology Review, 30(7), 890-905.

Publisher's Note Springer Nature remains neutral with regard to jurisdictional claims in published maps and institutional affiliations. 